\title{
Assessing individual dietary intake from common-plate meals: a new tool for an enduring practice
}

\author{
Kathleen Abu-Saad ${ }^{1, *}$, Danit R Shahar ${ }^{1}$, Heiger Abu-Shareb ${ }^{2}$, Hillel Vardi ${ }^{1}$, \\ Natalya Bilenko ${ }^{1,3}$ and Drora Fraser ${ }^{1}$ \\ 'S. Daniel Abraham International Center for Health and Nutrition, Faculty of Health Sciences, Ben-Gurion \\ University of the Negev, POB 653, Beer-Sheva 84105, Israel: ${ }^{2}$ Department of Epidemiology and Health Services \\ Evaluation, Faculty of Health Sciences, Ben-Gurion University of the Negev, Beer-Sheva, Israel: ${ }^{3}$ Ministry of \\ Health, Southern District, Beer-Sheva, Israel
}

Submitted 4 September 2008: Accepted 8 February 2009: First published online 1 May 2009

\begin{abstract}
Objective: The purposes of the present study were to estimate individual intake from common-plate meals among Bedouin Arabs using a modified $24 \mathrm{~h}$ recall questionnaire, and to evaluate reported energy intake (EI) by comparison with estimated energy requirement (EER).

Design: Weighed records were used to develop a method of quantifying intake from common plates. Reported EI and nutrient intakes were obtained from administration of the modified $24 \mathrm{~h}$ recall. The relative standard error (RSE) was used to evaluate the reliability of reported nutrient intakes. The FAO/WHO/ United Nations University and Oxford equations and reported physical activity levels were used to compute ratios of reported EI to BMR and EER.

Setting: Population centres of traditionally semi-nomadic Bedouin Arabs undergoing sedentarization/urbanization in southern Israel.

Subjects: A convenience sample of 451 adults (aged 19-82 years).

Results: Mean (SE) energy intake was 9648 (276) kJ/d (2306 (66) kcal/d) for men and 8230 (172) kJ/d (1967 (41) kcal/d) for women, of which carbohydrates accounted for $63-64 \%$. The nutrient intakes evaluated had RSE ratios of less than $25 \%$. EI:EER ratios ranged from 0.86 to 0.89 , and from 0.87 to 0.93 among non-dieters who ate the usual amount on the recall day.

Conclusions: The modified $24 \mathrm{~h}$ recall produced plausible estimates of energy and nutrient intakes, comparable to those obtained with the $24 \mathrm{~h}$ recall in other populations. The modified questionnaire makes an important contribution to facilitating large-scale nutritional surveillance in the Bedouin population, and may serve as a model for modifying dietary instruments to quantify individual intake in other populations that practise common-plate eating.
\end{abstract}

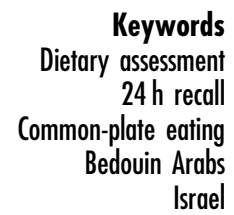

The Negev Bedouin Arabs in southern Israel, a traditionally semi-nomadic population, historically ate their meals from common plates. Despite the processes of sedentarization, modernization and urbanization that have occurred in this population over the past 50 years, common-plate eating remains an enduring practice. Dietary surveillance among Negev Bedouin Arabs has been hampered by the lack of an appropriate dietary assessment instrument for quantifying intake at the individual level ${ }^{(1)}$, thus current comprehensive nutrient intake data for this population are lacking.

Common-plate eating occurs in many parts of the world, but little work has been done to develop dietary assessment methods for quantitatively measuring individual food intake that are practical for use in epidemiological studies ${ }^{(2-4)}$.
The $24 \mathrm{~h}$ recall questionnaire is the main tool for dietary surveillance and monitoring dietary intake over time ${ }^{(5,6)}$. It is based on identifying foods eaten and their portion sizes served and eaten individually in a $24 \mathrm{~h}$ period preceding the interview. The traditional $24 \mathrm{~h}$ recall is not designed to measure food intake in societies in which common-plate eating is practised.

During recent decades, chronic disease rates among the Bedouin have been on the increase ${ }^{(7-10)}$, as they have in many of the populations that practise common-plate eating $^{(11,12)}$. Thus, the development of appropriate dietary assessment instruments that are practical for use in large-scale dietary surveillance has become increasingly important. To the best of our knowledge, no dietary assessment tool has ever been adapted and/or used for 
measuring individual food intake in this population. In the present paper, we describe the modification of the $24 \mathrm{~h}$ recall for quantifying individual intake from common-plate meals, present the results from the administration of the modified $24 \mathrm{~h}$ recall among a sample of Bedouin adults, and compare reported energy intakes (EI) with estimated energy requirements (EER) derived from the calculation of BMR and reported physical activity levels (PAL).

\section{Population and methods}

\section{The population and food culture}

The history and characteristics of the Bedouin Arabs living in the Negev desert in southern Israel have been described elsewhere ${ }^{(9,13,14)}$. When the Bedouin Nutritional Study (BNS) was conducted (2001-3), the Negev Bedouin population numbered 138000 of whom $60 \%$ lived in government-planned towns. The remaining $40 \%$ lived more traditionally in unrecognized villages not connected to local and national planning and communications infrastructures. The Negev Bedouin have the lowest socio-economic level of any population group in Israel, reflected in educational, employment and income levels ${ }^{(15,16)}$.

Traditionally, Bedouin food culture was well adapted to a semi-nomadic life which involved seasonal migration and living in tents with limited household utensils that were easy to transport. The most common traditional meal patterns consisted of either one main dish served on a large platter or of one or more dishes of cooked foods or salads in common service dishes. Main dish meals were usually eaten with the hand, and the rules of hygiene required that a person eat only from the part of the plate directly in front of him/her. In the second type of meal, bite-sized portions of flat bread were used as utensils for dipping in or scooping up food from common service dishes. The bread was consumed along with the food it held. Since many of the foods eaten from common plates with bread were sauce-like or liquid, it was not possible for a person eating with others to visualize how much he or she consumed individually.

Due to the absence of $40 \%$ of the population from census data, the use of standard methods of drawing a random sample (e.g. street addresses from voter registration lists, telephone directories, etc.) would have systematically excluded all those who live in settings that lack official mapping/street addresses and land-line telephones. To obtain a sample that included Bedouin from both recognized and unrecognized localities, we drew the study population from healthy Bedouin adults visiting patients at Soroka University Medical Center, the only regional hospital serving the southern (Negev) region of Israel, and adults (primarily women) attending Maternal and Child Health Care clinics in Bedouin towns.
The hospital and clinics serve the Bedouin from both the government-planned towns and the surrounding unrecognized villages, and thus provided us with access to a broad geographical cross-section of the population.

We enrolled adults aged 19 years and above who consented to provide dietary intake information. Data were collected on all days of the week, including weekend days.

\section{Updating the food and nutrient database}

The S. Daniel Abraham International Center for Health and Nutrition food composition tables, which are currently based on the US Department of Agriculture (USDA) Nutrient Database for Standard Reference Release 19, were modified to include Israeli-manufactured foods and common recipes ${ }^{(17)}$, but did not include Bedouin foods. We recorded recipes in homes of Bedouin women who cooked a dish, while the research team member weighed and measured the ingredients using digital scales and standardized measuring tools. Cooking times were recorded, and foods were weighed before and after cooking. We thus added 145 Bedouin recipes/foods/beverages to the database prior to beginning and throughout the dietary assessment process. Recipes were calculated using another computer system we developed based on the concept of the American Food Information Analysis System (FIAS) program ${ }^{(18)}$. Trained nutritional data entry coders did the data entry.

\section{Quantifying food intake}

Field tests were conducted in eleven households in three different Bedouin communities to determine what quantifiable information Bedouin could give us on their food intake at the individual level. Foods and beverages eaten in individual servings (e.g. pieces of fruits, sandwiches, meat not in stews) were easily quantified using the USDA $\operatorname{method}^{(19)}$. Respondents were also able to estimate the quantity of bread they ate, since generally people take portions of bread (e.g. a half or whole pita), which they consume individually. Since bread is used as the utensil for eating from common plates, it also serves as the vehicle determining the amount of the common-plate foods consumed, and could thus be used as the means for quantifying the intake of these foods. To determine the "carrying capacity' of bread for common-plate foods of different consistencies, the BNS Bedouin study staff were trained to conduct weight tests under natural eating conditions among a pool of volunteers recruited from their nuclear and extended families by weighing the bread and common-plate food before and after a meal in which a single common-plate dish was served. Weighings were conducted among adults in five field locations in both urban and rural settings. Multiple weighings of twenty-eight common-plate foods of differing consistencies were carried out in a total of seventeen households. Analysis of these data showed that most common-plate foods fell into two main categories: A, 
solid/semi-solid (e.g. egg dishes, humus salad, semi-solid dips, sauces containing chunks of meat and/or vegetables, thick cracked-wheat or lentil sauces); and B, liquid (e.g. buttermilk sauces, thin vegetable sauces made with potherbs not containing solid chunks). Aggregated averages of the weight data were used to establish the 'carrying capacity' of bread, expressed as food:bread ratios, for these two categories of foods (category A, $1.3 \mathrm{~g}$ food: $1 \cdot 0 \mathrm{~g}$ bread; category $\mathrm{B}, 1 \cdot 0 \mathrm{~g}$ food: $1 \cdot 0 \mathrm{~g}$ bread). During the pilot and throughout the BNS data collection, the Bedouin BNS study coordinator and a registered dietitian reviewed the results produced by the food:bread ratios. For foods with different/unique consistencies (e.g. dried thyme mixed with olive oil) or for which the standard food:bread ratios produced implausible results, additional weighings were conducted under natural eating conditions and specific food:bread ratios set.

\section{Modification of the US Department of Agriculture $24 \mathrm{~b}$ recall questionnaire}

The USDA $24 \mathrm{~h}$ recall questionnaire was modified to allow for recording of the three eating practices of the population: (i) eating an item as an individual portion; (ii) eating from a common-plate with bread; or (iii) eating directly from a large platter. We used the multi-pass method $^{(19)}$ to administer the modified USDA $24 \mathrm{~h}$ recall questionnaire. At the appropriate stage, the interviewers determined which foods were eaten together in one sitting and whether the foods had been consumed with bread as the utensil, individually or with others eating from the same dishes. All items consumed with bread from common plates in a single meal were enclosed by brackets. The total amount of bread the respondent consumed during that meal was obtained.

To estimate the portion size for each of the foods eaten with bread as the utensil in multi-dish meals eaten with others, the interviewer asked if the respondent ate a relatively smaller, medium or larger portion (or equal portions) from each dish. The total amount of bread was then divided by the relative portions given, using 1 for small, 2 for medium and 3 for large. The quantity of food eaten from each dish was calculated on the basis of the food:bread ratio for the consistency category of the food (as described above), and multiplied by the amount of bread (in grams) eaten with each dish.

For meals eaten from a single large common platter, pictures with different relative portions removed from the platter were used as reporting aids. Portion sizes for items consumed individually, rather than from common plates, were reported in the standard way.

The modified $24 \mathrm{~h}$ recall questionnaire was piloted among forty Bedouin adults. The results confirmed that individuals were able to estimate the amount of bread they ate at a meal and were able to estimate the relative proportion they consumed from each dish of a commonplate meal with bread.

\section{Administration of the modified $24 \mathrm{~b}$ recall}

Trained interviewers conducted the interviews in Arabic using a USDA food book and a food models/portion-size booklet modified to include common Israeli foods and Bedouin foods, utensils and portion sizes. Upon completion of the $24 \mathrm{~h}$ recall, a number of questions on general health status were asked, a physical activity questionnaire was administered, and the respondents' weight (in light street clothing) and height were measured using a portable digital scale and collapsible measuring stick. Two additional $24 \mathrm{~h}$ recalls were completed on nonconsecutive days among a subsample of forty respondents who agreed to be interviewed at home.

\section{Quality control}

Quality control was applied at four stages. First, each interview was checked for missing data within 1-3d of the interview. Second, after data entry, the BNS study coordinator, who had extensive knowledge of Bedouin foods and the process for quantifying intake from common plates, edited each questionnaire for accurate data entry and appropriate application of the common-plate quantification method. Requests for corrections were then returned to the coders and re-checked. At the third stage, registered dietitians edited each questionnaire, returned corrections to the coders and re-checked corrected data entries; and, at the final stage, the BNS study coordinator and registered dietitians made cross-interview checks to detect unusual nutrient or food model values.

\section{Physical activity levels}

We used a physical activity questionnaire based upon a synthesis of previously validated international questionnaires $^{(20-22)}$, modified for use in Israel ${ }^{(23)}$. It included questions about the time spent in and intensity of work, recreational, leisure-time and household activities, further modified to capture specific activities associated with Bedouin lifestyle (e.g. herding, washing clothes by hand). The definitions of the joint FAO/WHO/United Nations University (UNU) report on human energy requirements ${ }^{(24)}$ were used to classify physical activities as sedentary/light (non-strenuous occupations, no regular leisure-time or lifestyle-required physical exercise); active/moderately active (moderate occupational exertion or moderate/vigorous leisure activity $\geq 1 \mathrm{~h} / \mathrm{d}$ ); or vigorously active (very strenuous occupational or leisure activities several hours daily).

\section{Statistical analysis}

Descriptive statistics were used to provide a profile of the sample's demographic characteristics, eating patterns and nutrient intakes. We tested for differences in eating patterns by categorical demographic variables using the $\chi^{2}$ statistic and by continuous demographic variables using Student's $t$ test. Following the method of the National Health and Nutrition Examination Survey (NHANES) 1999-2000, we used a relative standard error (RSE; ratio of 
Table 1 Selected characteristics of the Bedouin Nutrition Study participants ( $n$ 451)

\begin{tabular}{|c|c|c|}
\hline Demographic characteristic & $n$ or Mean & $\%$ or SD \\
\hline Women ${ }^{*}$ & 302 & $67 \cdot 0$ \\
\hline Age (years) $\dagger$ & $33 \cdot 8$ & $10 \cdot 3$ \\
\hline Education (years)t, $\ddagger$ & $8 \cdot 4$ & $4 \cdot 0$ \\
\hline BMI $\left(\mathrm{kg} / \mathrm{m}^{2}\right) \dagger$ & $26 \cdot 0$ & $4 \cdot 7$ \\
\hline Urban settlement* & 293 & $65 \cdot 0$ \\
\hline \multicolumn{3}{|l|}{ Amount of food eaten on recall day ${ }^{*}$} \\
\hline Usual amount & 349 & $77 \cdot 4$ \\
\hline Less than usual & 83 & $18 \cdot 4$ \\
\hline More than usual & 19 & $4 \cdot 2$ \\
\hline Currently dieting* & 35 & $7 \cdot 8$ \\
\hline Pregnant or breast-feeding* & 162 & $36 \cdot 1$ \\
\hline Taking a vitamin supplement* & 72 & $16 \cdot 1$ \\
\hline \multicolumn{3}{|l|}{ Eating patterns } \\
\hline Number of eating occasions per questionnairet & $5 \cdot 07$ & $1 \cdot 8$ \\
\hline Total number of items per questionnaire/dt & $14 \cdot 0$ & $4 \cdot 1$ \\
\hline Questionnaires with one or more common-plate eating occasions* & 396 & $87 \cdot 8$ \\
\hline
\end{tabular}

${ }^{*}$ Data presented are $n$ and \%.

tData presented are mean and SD.

fData available for 108 men and 119 women.

the standard error of the mean to the mean, multiplied by 100) of greater than $25 \%$ as the statistical criterion to define unreliable nutrient intake estimates ${ }^{(25)}$. To evaluate the plausibility of the reported EI obtained from the modified $24 \mathrm{~h}$ recall questionnaire, we calculated the EER using the FAO/WHO/UNU equations ${ }^{(24)}$, which are based on the Schofield equations ${ }^{(26)}$, to estimate the BMR, and then multiplied it by the appropriate PAL factor based on respondents' reported levels of physical activity. The PAL factors were $1.53,1.76$ and $2 \cdot 25$ for sedentary/light activity, active/moderately active or vigorously active lifestyles, respectively, as defined by the FAO/WHO/UNU report on human energy requirements ${ }^{(24)}$. The respondents' reported EI was then divided by their EER to obtain the EI:EER ratio. Owing to concerns that the Schofield equations overestimate BMR in non-European populations, the Oxford equations ${ }^{(27)}$ were developed based upon a database of measured BMR data that included a better representation of Asian and other non-European populations. Thus, we also used the Oxford equations to calculate the BMR and EI:EER ratios for our sample. Women who indicated that they were pregnant and breast-feeding on the questionnaire were excluded from this analysis. Student's $t$ tests and ANOVA were used to determine whether or not mean EI:EER ratios differed by sex, BMI (above or below median BMI), dieters and non-dieters, and reported eating of 'usual amount' on the day covered by the $24 \mathrm{~h}$ recall. Among the forty respondents who completed three repeat $24 \mathrm{~h}$ recalls, we computed the within-person $\mathrm{CV}$ for selected nutrients to assess the level of day-to-day variability in nutrient intakes using Generalized Estimating Equations (GEE) in the STATA statistical software package version $9 \cdot 2$ (StataCorp LP, College Station, TX, USA). All other statistical analyses were conducted using the SPSS statistical software package version $14 \cdot 0$ (SPSS Inc., Chicago, IL, USA), using $P<0.05$ to indicate significance.

\section{Results}

The total BNS sample included 519 participants. We excluded forty-five respondents interviewed during the Islamic month of Ramadan who were fasting from sunrise until sunset. Of the remaining participants, 451 (95\%) completed at least one reliable $24 \mathrm{~h}$ recall and were included in the analysis.

The demographic characteristics of the sample are presented in Table 1 . The respondents' age distribution ranged from 19 to 82 years with a mean of 34 years. Only $3 \%$ of the sample had BMI below $19 \cdot 0 \mathrm{~kg} / \mathrm{m}^{2}$, while over $40 \%$ had BMI above $26.0 \mathrm{~kg} / \mathrm{m}^{2}$. More than $75 \%$ of participants reported eating the usual amount on the day of dietary recall, and approximately $8 \%$ reported currently dieting. The proportion who reported taking a vitamin supplement was low, and was concentrated among women who were pregnant or breast-feeding. In the remainder of the sample ( $n$ 286), only $6 \cdot 3 \%$ reported using vitamin supplements.

With regard to eating patterns, $88 \%$ reported eating at least one common-plate meal, and this proportion was higher among those living in rural (94\%) than in urban ( $85 \%)$ communities $\left(\chi^{2}=7 \cdot 82, \mathrm{df}=1, P=0 \cdot 005\right)$. Those who reported eating common-plate meals did not differ significantly by sex, age or years of education from those who did not report eating common-plate meals.

Table 2 contains the means, standard errors and medians for the dietary intakes of selected nutrients for men and women. All intake estimates have RSE ratios of less than $25 \%$. Carbohydrate intake accounted for $\sim 63 \%$ of total energy.

Table 3 presents the mean EI for men and women (excluding pregnant and breast-feeding women) and EER calculated using the FAO/Schofield and the Oxford equations and respondents' reported PAL. Low proportions 
Table 2 Dietary intake of selected nutrients among Bedouin men and women in the Bedouin Nutrition Study

\begin{tabular}{|c|c|c|c|c|c|c|}
\hline & \multicolumn{3}{|c|}{ Men ( $n$ 149) } & \multicolumn{3}{|c|}{ Women (n 302) } \\
\hline & Mean & SE & Median & Mean & SE & Median \\
\hline Energy (kJ/d) & 9653 & 275 & 9665 & 8234 & 171 & 7836 \\
\hline Energy (kcal/d) & 2306 & $65 \cdot 7$ & 2309 & 1967 & $40 \cdot 9$ & 1872 \\
\hline Protein $(\mathrm{g} / \mathrm{d})$ & $77 \cdot 4$ & $2 \cdot 8$ & $72 \cdot 8$ & $63 \cdot 6$ & $1 \cdot 6$ & $59 \cdot 0$ \\
\hline Carbohydrates $(\mathrm{g} / \mathrm{d})$ & $357 \cdot 4$ & $10 \cdot 1$ & $354 \cdot 3$ & $312 \cdot 0$ & $6 \cdot 3$ & $306 \cdot 3$ \\
\hline Fat $(g / d)$ & $69 \cdot 3$ & $3 \cdot 2$ & $66 \cdot 0$ & $57 \cdot 0$ & $1 \cdot 8$ & $51 \cdot 3$ \\
\hline Cholesterol (mg/d) & $196 \cdot 3$ & $17 \cdot 0$ & $140 \cdot 7$ & $184 \cdot 1$ & $10 \cdot 8$ & $111 \cdot 4$ \\
\hline Total SFA $(\mathrm{g} / \mathrm{d})$ & $16 \cdot 4$ & $1 \cdot 0$ & $14 \cdot 7$ & $14 \cdot 7$ & 0.5 & $13 \cdot 1$ \\
\hline Total MUFA (g/d) & $26 \cdot 5$ & $1 \cdot 4$ & $23 \cdot 5$ & $22 \cdot 8$ & 0.9 & $18 \cdot 7$ \\
\hline Total PUFA ( $\mathrm{g} / \mathrm{d}$ ) & $20 \cdot 8$ & $1 \cdot 2$ & $16 \cdot 8$ & $15 \cdot 5$ & 0.6 & $13 \cdot 5$ \\
\hline Dietary fibre $(\mathrm{g} / \mathrm{d})$ & $31 \cdot 3$ & $1 \cdot 7$ & $26 \cdot 0$ & $27 \cdot 1$ & 0.9 & $24 \cdot 2$ \\
\hline $\mathrm{Fe}(\mathrm{mg} / \mathrm{d})$ & $15 \cdot 0$ & $0 \cdot 7$ & $12 \cdot 1$ & $11 \cdot 4$ & 0.3 & $10 \cdot 4$ \\
\hline $\mathrm{Ca}(\mathrm{mg} / \mathrm{d})$ & $401 \cdot 5$ & $20 \cdot 3$ & $336 \cdot 1$ & $397 \cdot 0$ & $13 \cdot 6$ & 338.5 \\
\hline $\mathrm{Zn}(\mathrm{mg} / \mathrm{d})$ & $10 \cdot 5$ & 0.5 & $9 \cdot 0$ & $8 \cdot 3$ & $0 \cdot 3$ & $7 \cdot 2$ \\
\hline Vitamin C (mg/d) & $66 \cdot 5$ & $4 \cdot 6$ & $51 \cdot 2$ & $100 \cdot 1$ & $4 \cdot 8$ & $74 \cdot 2$ \\
\hline Vitamin E (mg/d) & $7 \cdot 4$ & $0 \cdot 4$ & $6 \cdot 2$ & $6 \cdot 9$ & $0 \cdot 2$ & $6 \cdot 0$ \\
\hline Thiamin $(\mathrm{mg} / \mathrm{d})$ & $1 \cdot 13$ & 0.05 & $1 \cdot 00$ & 0.94 & 0.03 & 0.87 \\
\hline Vitamin $B_{2}(\mathrm{mg} / \mathrm{d})$ & $1 \cdot 38$ & 0.07 & $1 \cdot 16$ & $1 \cdot 20$ & 0.04 & 1.06 \\
\hline Niacin $(\mathrm{mg} / \mathrm{d})$ & $19 \cdot 9$ & 0.9 & $18 \cdot 1$ & $15 \cdot 7$ & 0.5 & $14 \cdot 0$ \\
\hline Folate $(\mu \mathrm{g} / \mathrm{d})$ & $295 \cdot 9$ & $15 \cdot 5$ & $266 \cdot 2$ & $272 \cdot 0$ & $8 \cdot 9$ & $236 \cdot 1$ \\
\hline \multicolumn{7}{|l|}{$\%$ of total energy } \\
\hline Protein & $13 \cdot 5$ & 0.3 & $12 \cdot 6$ & $13 \cdot 1$ & 0.2 & $12 \cdot 5$ \\
\hline Carbohydrate & $62 \cdot 9$ & 0.9 & $63 \cdot 9$ & $64 \cdot 3$ & 0.5 & $64 \cdot 4$ \\
\hline Total fat & $25 \cdot 9$ & 0.8 & $25 \cdot 6$ & $25 \cdot 1$ & 0.5 & 24.9 \\
\hline
\end{tabular}

Table 3 Reported energy intake (EI), estimated energy requirement (EER) and ratios of reported El to estimated BMR and EER among men and women in the Bedouin Nutrition Study

\begin{tabular}{|c|c|c|c|c|}
\hline & \multicolumn{2}{|r|}{ Men } & \multicolumn{2}{|r|}{ Women* } \\
\hline & All $(n$ 149) & Usual intake/non-dieters ( $n$ 111) & All $(n 138)$ & Usual intake/non-dieters ( $n$ 101) \\
\hline \multicolumn{5}{|c|}{ Total reported El (kcal)† } \\
\hline Mean & 2306 & 2377 & 1894 & 2009 \\
\hline SD & 802 & 829 & 702 & 713 \\
\hline \multicolumn{5}{|c|}{$\begin{array}{l}\text { FAO estimates and ratios } \\
\text { EER }_{\text {FAO }}(\mathrm{kcal})+, \ddagger\end{array}$} \\
\hline Mean & 2797 & 2754 & 2204 & 2210 \\
\hline SD & 370 & 334 & 215 & 227 \\
\hline El:BMR ${ }_{F A O}$ & $1 \cdot 32$ & $1 \cdot 38$ & $1 \cdot 32$ & $1 \cdot 40$ \\
\hline $\mathrm{El}: \mathrm{EER}_{\mathrm{FAO}}$ & 0.83 & $0 \cdot 87$ & $0 \cdot 86$ & 0.91 \\
\hline \multicolumn{5}{|c|}{$\begin{array}{l}\text { Oxford estimates and ratios } \\
\text { EER }_{\mathrm{OXF}}(\mathrm{kcal})+, \S\end{array}$} \\
\hline Mean & 2707 & 2658 & 2147 & 2155 \\
\hline SD & 370 & 359 & 220 & 233 \\
\hline El:BMR $\mathrm{OXF}$ & $1 \cdot 37$ & $1 \cdot 43$ & $1 \cdot 36$ & $1 \cdot 44$ \\
\hline El:EER & $0 \cdot 86$ & 0.90 & $0 \cdot 89$ & 0.93 \\
\hline
\end{tabular}

${ }^{*}$ Pregnant and breast-feeding women were excluded from this analysis.

tTo convert to kJ, multiply kcal by $4 \cdot 184$.

$\ddagger$ Calculated using the FAO/WHO/United Nations University equations ${ }^{(24)}$ to obtain BMR, multiplied by physical activity level factor.

$\S$ Calculated using the Oxford equations ${ }^{(27)}$ to obtain BMR, multiplied by physical activity level factor.

reported engaging in physically demanding occupations (11\%) or household chores (e.g. hand-washing clothes, $6 \%)$ daily or in walking/exercise/sports for $\geq 1 \mathrm{~h} / \mathrm{d}$ (3\%); thus, $84 \%$ were classified as having sedentary/light activity, $16 \%$ as having moderately active lifestyles and none as having vigorously active lifestyles. We report both the EI:BMR and EI:EER ratios to facilitate comparisons with the results of other studies. The reported EI of the BNS respondents was closer to the EER calculated using the Oxford equations than to that using the FAO/Schofield equations, but with both equations was closer to the EER among respondents who ate the 'usual' amount on the recall day and were not dieting. The FAO/Schofield and Oxford EI:EER ratios were significantly higher among those who reported eating the 'usual' amount (0.88 and 0.91, respectively) than among those who reported eating less than usual' $(0 \cdot 70$ and $0 \cdot 72$, respectively) on the recall day $(P=0.001)$, and the trend for dieters and non-dieters was similar (data not shown). The mean EI:EER ${ }_{\mathrm{OXF}}$ ratios of those with $\mathrm{BMI} \geq 26 \cdot 0 \mathrm{~kg} / \mathrm{m}^{2} \quad\left(\mathrm{EI}: \mathrm{EER}_{\mathrm{OXF}}=0 \cdot 83\right)$ also 
Table 4 Mean and within-person CV of three repeat $24 \mathrm{~h}$ recalls for energy and selected nutrients among a subsample of Bedouin Nutrition Study participants

\begin{tabular}{|c|c|c|c|c|c|c|}
\hline & \multicolumn{3}{|c|}{ Men $(n$ 15) } & \multicolumn{3}{|c|}{ Women ( $n$ 25) } \\
\hline & Mean & SD & CV (\%) & Mean & SD & CV (\%) \\
\hline Energy (kJ/d) & 11133 & 2761 & $24 \cdot 8$ & 9736 & 2464 & $25 \cdot 3$ \\
\hline Energy (kcal/d) & 2661 & 660 & $24 \cdot 8$ & 2327 & 589 & $25 \cdot 3$ \\
\hline Protein $(\mathrm{g} / \mathrm{d})$ & $86 \cdot 7$ & $25 \cdot 2$ & $29 \cdot 1$ & $72 \cdot 5$ & $24 \cdot 5$ & $33 \cdot 8$ \\
\hline Carbohydrates $(\mathrm{g} / \mathrm{d})$ & $382 \cdot 6$ & $101 \cdot 5$ & $26 \cdot 5$ & $358 \cdot 0$ & $94 \cdot 0$ & $26 \cdot 3$ \\
\hline Fat $(\mathrm{g} / \mathrm{d})$ & $91 \cdot 2$ & $44 \cdot 8$ & $49 \cdot 1$ & $71 \cdot 3$ & $23 \cdot 4$ & $32 \cdot 9$ \\
\hline Cholesterol (mg/d) & $366 \cdot 2$ & $229 \cdot 7$ & $62 \cdot 7$ & $228 \cdot 5$ & $192 \cdot 5$ & $84 \cdot 3$ \\
\hline Total SFA $(\mathrm{g} / \mathrm{d})$ & $20 \cdot 9$ & $8 \cdot 3$ & $39 \cdot 6$ & $19 \cdot 0$ & $7 \cdot 3$ & $38 \cdot 4$ \\
\hline Total MUFA (g/d) & $31 \cdot 6$ & $13 \cdot 7$ & $43 \cdot 3$ & $26 \cdot 2$ & 9.5 & $36 \cdot 1$ \\
\hline Total PUFA (g/d) & $31 \cdot 9$ & $24 \cdot 2$ & $75 \cdot 8$ & $20 \cdot 7$ & $10 \cdot 1$ & $49 \cdot 0$ \\
\hline Dietary fibre $(\mathrm{g} / \mathrm{d})$ & $27 \cdot 2$ & $8 \cdot \overline{8}$ & $32 \cdot 2$ & $26 \cdot 4$ & $8 \cdot 1$ & $30 \cdot 8$ \\
\hline $\mathrm{Ca}(\mathrm{mg} / \mathrm{d})$ & $425 \cdot 2$ & $150 \cdot 8$ & $35 \cdot 5$ & $478 \cdot 0$ & $224 \cdot 8$ & $47 \cdot 0$ \\
\hline $\mathrm{Fe}(\mathrm{mg} / \mathrm{d})$ & $13 \cdot 4$ & $4 \cdot 3$ & $31 \cdot 6$ & $11 \cdot 8$ & $4 \cdot 4$ & $37 \cdot 2$ \\
\hline $\mathrm{Zn}(\mathrm{mg} / \mathrm{d})$ & $9 \cdot 4$ & $2 \cdot 8$ & $29 \cdot 6$ & $8 \cdot 3$ & 3.5 & $42 \cdot 2$ \\
\hline Vitamin A (IU) & 6749 & 19297 & 286 & 5870 & 6737 & 115 \\
\hline Vitamin C $(\mathrm{mg} / \mathrm{d})$ & $86 \cdot 8$ & 63.9 & $73 \cdot 6$ & $114 \cdot 0$ & $71 \cdot 4$ & $62 \cdot 6$ \\
\hline Vitamin $E(m g / d)$ & $9 \cdot 9$ & $6 \cdot 4$ & $46 \cdot 4$ & $8 \cdot 7$ & $5 \cdot 2$ & $39 \cdot 9$ \\
\hline Thiamin $(\mathrm{mg} / \mathrm{d})$ & $1 \cdot 08$ & $0 \cdot 36$ & $33 \cdot 4$ & $1 \cdot 00$ & 0.31 & $31 \cdot 3$ \\
\hline Vitamin $B_{2}(\mathrm{mg} / \mathrm{d})$ & $1 \cdot 69$ & $0 \cdot 81$ & $47 \cdot 9$ & 1.53 & 0.92 & $60 \cdot 2$ \\
\hline Niacin $(\mathrm{mg} / \mathrm{d})$ & $18 \cdot 8$ & $7 \cdot 1$ & $37 \cdot 8$ & $16 \cdot 2$ & $6 \cdot 8$ & $42 \cdot 2$ \\
\hline Folate $(\mu \mathrm{g} / \mathrm{d})$ & $337 \cdot 5$ & $197 \cdot 9$ & $58 \cdot 7$ & $332 \cdot 5$ & $162 \cdot 2$ & $48 \cdot 8$ \\
\hline
\end{tabular}

differed significantly from those with $\mathrm{BMI}<26 \cdot 0 \mathrm{~kg} / \mathrm{m}^{2}$ (EI:EER $\mathrm{OXX}=0 \cdot 90, P=0 \cdot 041$ ).

The mean intakes of selected nutrients and the withinperson $\mathrm{CV}$ for three repeat $24 \mathrm{~h}$ recalls administered to a subsample of forty respondents are presented in Table 4 . The CV for energy and macronutrients ranged from $24 \cdot 8 \%$ to $49 \cdot 1 \%$, those for micronutrients ranged from $31 \cdot 3 \%$ to $286 \cdot 0 \%$.

\section{Discussion}

We present a modified USDA $24 \mathrm{~h}$ recall questionnaire that quantifies individual intake from common-plate meals among the Negev Bedouin Arab population in southern Israel. Since $88 \%$ of the respondents reported eating common-plate meals on the recall day, we can confirm that common-plate eating is a widespread and enduring practice among Negev Bedouin adults and that an appropriate dietary assessment instrument for common-plate eating is needed. In addition, this population has undergone a major transition from semi-nomadic pastoralists and agriculturalists to sedentarized/urbanized wage labourers, and the transition has been accompanied by dramatically rising rates of chronic diseases ${ }^{(7-10,13,14)}$. It is reasonable to assume that life changes, including dietary changes, have contributed to increases in chronic disease rates. Thus, an appropriate tool for nutritional surveillance, such as the $24 \mathrm{~h}$ recall questionnaire, is crucial for assessing nutrient intake quantity/quality and identifying dietary trends. It will also enable health-care professionals to evaluate the efficacy of interventions targeted at disease prevention and health promotion ${ }^{(11,12)}$.
The dietary assessment tools developed in Europeanorigin cultures are not suitable for measuring individual dietary intake in contexts in which common-plate eating is practised. Alternative methodologies have been developed, ranging from distribution algorithms ${ }^{(3)}$ to observing subjects while eating ${ }^{(2,4)}$. Generally, these methodologies are quite costly and thus infeasible for large epidemiological studies or ongoing nutritional surveillance, particularly in developing countries where common-plate eating is more likely to be practised.

The modified $24 \mathrm{~h}$ recall used among Bedouin adults produced estimates of individual nutrient intakes that were comparable in terms of plausibility of reported EI and day-to-day within-person variation to those of the nutrient intake estimates obtained with the original USDA $24 \mathrm{~h}$ recall in other populations. The fact that respondents tend to underestimate their EI with the $24 \mathrm{~h}$ recall has been well documented, in both developed ${ }^{(5,28-30)}$ and developing countries/populations ${ }^{(31-33)}$. We evaluated the plausibility of the reported EI from the modified $24 \mathrm{~h}$ recall by comparing it with EER computed using the FAO/ $\mathrm{WHO} / \mathrm{UNU}^{(24)}$ and the Oxford ${ }^{(27)}$ BMR equations. Several of the older equations for calculating BMR (e.g. HarrisBenedict ${ }^{(34)}$ ), including the $\mathrm{FAO} / \mathrm{WHO} / \mathrm{UNU}$ equations based on Schofield's BMR data collected in the $1930 \mathrm{~s}^{(26)}$, have been shown to overestimate energy requirements in modern populations, and particularly those of nonEuropean origin ${ }^{(26,27,35-38)}$. The Oxford equations were developed more recently using a data set of 10552 BMR measurements that included a much larger number of non-European subjects ${ }^{(27)}$. In the present study, the BMR calculated according to the Oxford equations was closer to the EI of the BNS respondents than the BMR calculated 
according to other equations, as well as more sensitive to differences in EI:EER ratios by BMI. The EI:EER and EI:BMR ratios we obtained using both the FAO (Schofield) and Oxford BMR equations were well within the range of EI:EER and EI:BMR ratios reported in the literature for $24 \mathrm{~h}$ recall questionnaires ${ }^{(39)}$, particularly when our analysis was limited to non-dieters who ate the usual amount (EI:EER $\mathrm{FAO}=0.87,0.91$; and EI:EER $\mathrm{OXX}_{\mathrm{F}}=0.90$, 0.93; men and women, respectively). A review of studies validating reported energy intake produced a mean EI:EER of 0.87 in studies comparing the reported EI from $24 \mathrm{~h}$ recalls with EER measured by doubly labelled water $^{(40)}$. Among the studies comparing EI from $24 \mathrm{~h}$ recalls with estimated BMR, EI:BMR ratios ranged from 1.37 to 1.51 for men and from 1.09 to 1.39 for women. Comparison of reported EI from one $24 \mathrm{~h}$ recall in NHANES III with BMR estimated using Schofield's equations resulted in mean EI:BMR ratios of 1.47 and 1.26 for men and women, respectively ${ }^{(5)}$. In our study, the mean EI:BMR ratios calculated using the $\mathrm{FAO} / \mathrm{WHO} / \mathrm{UNU}$ equations based on Schofield's equations were 1.32 for both men and women. Similar to our findings, Briefel et al. reported higher EI:BMR ratios among those who were not dieting, who reported eating the usual amount on the recall day, and who were not overweight ${ }^{(5)}$.

Another characteristic of the $24 \mathrm{~h}$ recall and other $1 \mathrm{~d}$ dietary records is that they give poor estimates of an individual's habitual diet ${ }^{(41,42)}$, and therefore repeat $24 \mathrm{~h}$ recalls from a subsample of respondents have been used to estimate within-person variance in day-to-day dietary intake $^{(43-46)}$. Based upon a subsample of forty BNS respondents for whom we had three repeat $24 \mathrm{~h}$ recalls on non-consecutive days, we computed the within-person variation in day-to-day nutrient intakes. Our results were within the range of the within-person levels of variation from $1 \mathrm{~d}$ intake recalls and records found in the published literature ${ }^{(41,43-45,47,48)}$. Day-to-day variation in intakes are on the level of $25 \%$ or higher for energy and macronutrients ${ }^{(41,43,44,47)}$. The $\mathrm{CV}$ are higher for many micronutrients, particularly those that are found in high amounts in a relatively small number of foods ${ }^{(41,48)}$.

The nutrient intake estimations of the BNS respondents met the criterion for reliable estimates used for nutritional surveillance with the $24 \mathrm{~h}$ recall in the NHANES studies. EI in the BNS sample was similar to EI reports for adults based on one $24 \mathrm{~h}$ recall in the NHANES data ${ }^{(25,49)}$; however, the macronutrient distribution differed. BNS respondents obtained a higher proportion of their energy from carbohydrates and lower proportions from protein and fats (63-64\%, 13\% and 25-26\%, respectively) than NHANES respondents (48-50\%, 15-16\% and 34\%, respectively) ${ }^{(50)}$. When we compared the macronutrient distribution of a subsample of BNS respondents (aged $\geq 35$ years) with that of Jewish Israelis of the same age group, the same trends were found, and the differences were statistically significant ${ }^{(9)}$. BNS macronutrient intakes showed distributions closer to those reported in middleincome/developing countries (e.g. Iran ${ }^{(51)}$, Korea ${ }^{(52)}$, Chile $^{(53)}$, western Mali ${ }^{(54)}$ ) than to those in high-income/ developed countries ${ }^{(9,50)}$.

The study has a number of limitations. The BNS sample was not drawn randomly, given the practical, logistical difficulties of randomizing sample selection in this population, so the generalizability of the results is limited. Nevertheless, the sample included a broad geographical cross-section of Negev Bedouin adults from both rural and urban settings among whom the modified $24 \mathrm{~h}$ recall was successfully administered, demonstrating the feasibility of using this tool to estimate individual intake from common-plate meals in the Negev Bedouin population. As with the original $24 \mathrm{~h}$ recall, the EI:EER ratios below $1 \cdot 0$ obtained with the modified $24 \mathrm{~h}$ recall suggest that respondents tend to underestimate EI; and one $24 \mathrm{~h}$ recall does not necessarily reflect habitual intake. These factors must always be taken into account when analysing and interpreting short-term dietary intake data. At the same time, the levels of EI underestimation and day-to-day withinperson variation in food intake we found with the modified $24 \mathrm{~h}$ recall were well within the ranges reported for the original $24 \mathrm{~h}$ recall in a variety of other populations.

The modified $24 \mathrm{~h}$ recall instrument, which quantifies individual dietary intake from common-plate meals, has the potential to make an important contribution to facilitating large-scale nutritional surveillance in the Negev Bedouin Arab population. Additional dietary studies among the Bedouin are needed in order to further refine and validate the methods of quantifying individual intake from common plates, and future nutritional surveillance studies should include a larger number of repeat $24 \mathrm{~h}$ recalls, which would facilitate the estimation of usual nutrient intakes. It may also be possible to adapt the modified $24 \mathrm{~h}$ recall to other populations where bread is used for eating from common plates by developing local food:bread ratios. In addition, the model may be useful for developing dietary assessment methods in other common-plate eating contexts by identifying some food/ meal component that can be quantified individually and can also be utilized as a vehicle for quantifying the foods eaten from common plates.

\section{Acknowledgements}

This research was supported by funds from the S. Daniel Abraham International Center for Health and Nutrition, Department of Epidemiology and Health Services Evaluation, Faculty of Health Sciences, Ben-Gurion University of the Negev, Israel. None of the authors have any financial conflicts of interest. K.A.-S. contributed to the study conception and design, the analysis and interpretation of data, and the drafting of the paper. D.R.S. contributed to the interpretation of the data and the 
drafting of the paper. H.A.-S. contributed to the study conception and design and interpretation of the data. H.V. contributed to the conception and design of the study and the analysis and interpretation of the data. N.B. contributed to the conception of the study and the interpretation of the data. D.F. contributed to the conception and design of the study, interpretation of the data, and the drafting of the paper. We are grateful to Dr Arkadi Bolotin for his assistance with data analysis in STATA. Manuscript preparation was supported by a post-doctoral grant from Mr Robert Arnow.

\section{References}

1. Groen JJ, Balough M, Levy M \& Yaron E (1964) Nutrition of the Bedouins in the Negev Desert. Am J Clin Nutr 14, $37-46$.

2. Harrison GG (1998) Experiences with dietary assessment in the Middle East. Public Health Rev 26, 55-63.

3. Hudson GJ (1995) Food intake in a West African village. Estimation of food intake from a shared bowl. Br J Nutr $\mathbf{7 3}$, 551-569.

4. Shankar AV, Gittelsohn J, Stallings R, West KP Jr, Gnywali T, Dhungel C \& Dahal B (2001) Comparison of visual estimates of children's portion sizes under both sharedplate and individual-plate conditions. J Am Diet Assoc 101 $47-52$.

5. Briefel RR, Sempos CT, McDowell MA, Chien S \& Alaimo K (1997) Dietary methods research in the third National Health and Nutrition Examination Survey: underreporting of energy intake. Am J Clin Nutr 65, 4 Suppl., 1203S-1209S.

6. Wright JD, Borrud LG, McDowell MA, Wang CY, Radimer K \& Johnson CL (2007) Nutrition assessment in the National Health and Nutrition Examination Survey 1999-2002. J Am Diet Assoc 107, 822-829.

7. Abou-Rbiah Y \& Weitzman S (2002) Diabetes among Bedouins in the Negev: the transition from a rare to a highly prevalent condition. Isr Med Assoc J 4, 687-689.

8. Cohen AD, Gefen K, Ozer A, Bagola N, Milrad V, Cohen L, Abu-Hammad T, Abu-Rabia Y, Hazanov I \& Vardy DA (2005) Diabetes control in the Bedouin population in southern Israel. Med Sci Monit 11, CR376-CR380.

9. Fraser D, Bilenko N, Vardy H, Abu-Saad K, Shai I, AbuShareb H \& Shahar DR (2008) Differences in food intake and disparity in obesity rates between adult Jews and Bedouins in southern Israel. Ethn Dis 18, 13-18.

10. Tamir O, Peleg R, Dreiher J et al. (2007) Cardiovascular risk factors in the Bedouin population: management and compliance. Isr Med Assoc J 9, 652-655.

11. Choi BC, McQueen DV, Puska P et al. (2008) Enhancing global capacity in the surveillance, prevention, and control of chronic diseases: seven themes to consider and build upon. J Epidemiol Community Health 62, 391-397.

12. Musaiger AO (2002) Diet and the prevention of coronary heart disease in the Arab Middle East countries. Med Principles Pract 11, Suppl. 2, 9-16.

13. Abu-Saad K, Weitzman S, Abu-Rabiah Y, Abu-Shareb H \& Fraser D (2001) Rapid lifestyle, diet and health changes among urban Bedouin Arabs of southern Israel. FNA 28, $45-52$.

14. Fraser D, Abu-Saad K \& Abu-Shareb H (2001) The relative importance of traditional and 'modern' foods for Israeli Negev Bedouins - a population in transition. Nutr Metab Cardiovasc Dis 11, Suppl. 4, 66-69.

15. The Center for Bedouin Studies and Development (2004) Statistical Yearbook of the Negev Bedouin, No. 2. Beer
Sheva: The Center for Bedouin Studies and Development and the Negev Center for Regional Development, BenGurion University of the Negev.

16. Swirski S \& Hasson Y (2006) Invisible Citizens: Israel Government Policy Toward the Negev Bedouin. Beer-Sheva: Hamachpil Ltd.

17. Shai I, Vardi H, Shahar DR, Azrad AB \& Fraser D (2003) Adaptation of international nutrition databases and dataentry system tools to a specific population. Public Health Nutr 6, 401-406.

18. US Department of Agriculture, Human Nutrition Information Service (1996) Food Intake Analysis System, Version 3. Houston, TX: University of Texas Health Science Center at Houston School of Public Health.

19. Conway JM, Ingwersen LA, Vinyard BT \& Moshfegh AJ (2003) Effectiveness of the US Department of Agriculture 5 -step multiple-pass method in assessing food intake in obese and nonobese women. Am J Clin Nutr 77, 1171-1178.

20. Pols MA, Peeters PH, Ocké MC, Bueno-de-Mesquita HB, Slimani N, Kemper HC \& Collette HJ (1997) Relative validity and repeatability of a new questionnaire on physical activity. Prev Med 26, 37-43.

21. Sesso HD, Paffenbarger RS \& Lee IM (2000) Physical activity and coronary heart disease in men: the Harvard Alumni Health Study. Circulation 102, 975-980.

22. Wareham NJ, Jakes RW, Rennie KL, Mitchell J, Hennings S \& Day NE (2002) Validity and repeatability of the EPICNorfolk Physical Activity Questionnaire. Int J Epidemiol 31, 168-174

23. Azrad A (2002) Association between physical activity, energy balance, dietary habits and health-related parameters in a working population. Masters Thesis, Ben-Gurion University of the Negev.

24. Food and Agriculture Organization of the United Nations/ World Health Organization/United Nations University (2004) Human Energy Requirements: Report of a Joint FAO/WHO/UNU Expert Consultation. FAO Food and Nutrition Technical Report Series no. 1. Rome: FAO.

25. Wright JD, Wang CY, Kennedy-Stephenson J \& Ervin RB (2003) Dietary intake of ten key nutrients for public health, United States: 1999-2000. Adv Data 334, 17 Apr, 1-4.

26. Schofield WN, Schofield C \& James WPT (1985) Basal metabolic rate - review and prediction, together with an annotated bibliography of source material. Hum Nutr Clin Nutr 39, Suppl. 1, 5-41.

27. Henry CJK (2005) Basal metabolic rate studies in humans: measurement and development of new equations. Public Health Nutr 8, 1133-1152.

28. Novotny JA, Rumpler WV, Riddick H \& Herbert JR (2003) Personality characteristics as predictors of underreporting of energy intake on 24-hour dietary recall interviews. $J \mathrm{Am}$ Diet Assoc 103, 1146-1151.

29. Tooze JA, Subar AF, Thompson FE, Troiano R, Schatzkin A \& Kipnis V (2004) Psychosocial predictors of energy underreporting in a large doubly labeled water study. Am J Clin Nutr 79, 795-804.

30. Ferrari P, Slimani N, Ciampi A et al. (2002) Evaluation of under- and overreporting of energy intake in the 24-hour diet recalls in the European Prospective Investigation into Cancer and Nutrition (EPIC). Public Health Nutr 5, 1329-1345.

31. Azizi F, Esmaillzadeh A \& Mirmiran P (2005) Correlates of under- and over-reporting of energy intake in Tehranians: body mass index and lifestyle-related factors. Asia Pac J Clin Nutr 14, 54-59.

32. Mendez MA, Wynter S, Wilks R \& Forrester T (2004) Underand overreporting of energy is related to obesity, lifestyle factors and food group intakes in Jamaican adults. Public Health Nutr 7, 9-19. 
33. Scagliusi FB, Ferriollo E \& Lancha AH Jr (2006) Underreporting of energy intake in developing nations. Nutr Rev 64, 319-330.

34. Harris JA \& Benedict FG (1919) A Biometric Study of Basal Metabolism in Man. Publication no. 279. Washington, DC: Carnegie Institute of Washington.

35. Case KO, Brahler CJ \& Heiss C (1997) Resting energy expenditures in Asian women measured by indirect calorimetry are lower than expenditures calculated from prediction equations. J Am Diet Assoc 97, 1288-1292.

36. Douglas CC, Lawrence JC, Bush NC, Oster RA, Gower BA \& Darnell BE (2007) Ability of the Harris-Benedict formula to predict energy requirements differs with weight history and ethnicity. Nutr Res 27, 194-199.

37. Leung R, Woo J, Chan D \& Tang N (2000) Validation of prediction equations for basal metabolic rate in Chinese subjects. Eur J Clin Nutr 54, 551-554.

38. Owen OE, Holup JL, D'Alessio DA et al. (1987) A reappraisal of the caloric requirements of men. Am J Clin Nutr 46, 875-885.

39. Jonnalagadda SS, Mitchell DC, Smiciklas-Wright H, Meaker KB, Van Heel N, Karmally W, Ershow AG \& Kris-Etherton PM (2000) Accuracy of energy intake data estimated by a multiple-pass, 24-hr dietary recall technique. J Am Diet Assoc 100, 303-311.

40. Livingstone MBE \& Black AE (2003) Markers of the validity of reported energy intake. J Nutr 133, Suppl. 3, 895S-920S.

41. Hegsted DM (1982) The classic approach - the USDA nationwide food consumption survey. Am J Clin Nutr 35, $1302-1305$.

42. Todd KS, Hudes M \& Calloway DH (1983) Food intake measurement: problems and approaches. Am J Clin Nutr 37, 139-146.

43. Ortega MI \& Valencia ME (2002) Measuring the intakes of foods and nutrients of marginal populations in north-west Mexico. Public Health Nutr 5, 907-910.

44. Beaton GH, Milner J, Corey P et al. (1979) Sources of variance in 24-hour dietary recall data: implications for nutrition study design and interpretation. Am J Clin Nutr 32, 2546-2559.

45. Beaton GH, Milner J, McGuire V, Feather TE \& Little JA (1983) Source of variance in 24-hour dietary recall data: implications for nutrition study design and interpretation. Carbohydrate sources, vitamins and minerals. Am J Clin Nutr 37, 986-995.

46. Moshfegh A, Goldman J \& Cleveland L (2005) What We Eat in America, NHANES 2001-2002: Usual Nutrient Intakes from Food Compared to Dietary Reference Intakes. Washington, DC: US Department of Agriculture, Agricultural Research Service.

47. Block G \& Hartman AM (1989) Issues in reproducibility and validity of dietary studies. Am J Clin Nutr 53, 1133-1138.

48. Nelson M, Black AE, Morris JA \& Cole TJ (1989) Betweenand within-subject variation in nutrient intake from infancy to old age: estimating the number of days required to rank dietary intakes with desired precision. Am J Clin Nutr 50, $155-167$.

49. US Department of Agriculture, Agricultural Research Service (2003-2004) What we eat in America, NHANES 2003-2004: nutrient intakes Table 1 - mean amounts consumed per individual, one day, 2003-2004. http:// www.ars.usda.gov/SP2UserFiles/Place/12355000/pdf/ 0304/Table_1_NIF.pdf (accessed September 2008).

50. US Department of Agriculture, Agricultural Research Service (2003-2004) What we eat in America, NHANES 2003-2004: nutrient intakes Table 2 - mean amounts and percentages of calories from protein, carbohydrate, fat, and alcohol, one day, 2003-2004. http://www.ars.usda.gov/ SP2UserFiles/Place/12355000/pdf/0304/Table_2_NIF.pdf (accessed September 2008).

51. Mirmiran P, Esmaillzadeh A \& Azizi F (2006) Underreporting of energy intake affects estimates of nutrient intakes. Asia Pac J Clin Nutr 15, 459-464.

52. Kim J, Kim Y, Ahn Y, Paik H, Ahn Y, Tokudome Y, Hamajima N, Inoue M \& Tajima K (2003) Development of a food frequency questionnaire in Koreans. Asia Pac J Clin Nutr 12, 243-250.

53. Albala C, Vio F, Kain J \& Uauy R (2002) Nutrition transition in Chile: determinants and consequences. Public Health Nutr 5, 123-128.

54. Torheim LV, Barikmo I, Hatløy A, Diakité M, Solvoll K, Diarra MM \& Oshaug A (2001) Validation of a quantitative food-frequency questionnaire for use in Western Mali. Public Health Nutr 4, 1267-1277. 